\title{
Loss of Nationality and Psychoneurotic Identity
}

\author{
Yener Özen* \\ Department of Educational Sciences, Kyrgyzstan-Turkey Manas University, Turkey
}

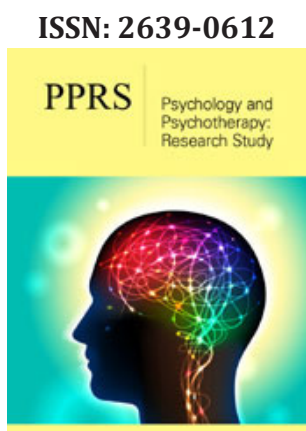

*Corresponding author: Yener Özen, Department of Educational Sciences, Kyrgyzstan-Turkey Manas University, Turkey

Email: yener.ozen@manas.edu.kg

Submission: 眥 December 05, 2019

Published: 眥December 13, 2019

Volume 3 - Issue 2

How to cite this article: Yener Özen. Loss of Nationality and Psychoneurotic Identity. Psychol Psychother Res Stud. 3(2).PPRS.000558.2019.

DOI: 10.31031/PPRS.2019.03.000558

Copyright@ Yener Özen, This article is distributed under the terms of the Creative Commons Attribution 4.0 International License, which permits unrestricted use and redistribution provided that the original author and source are credited.

\begin{abstract}
"Identity" is one of the most attractive and interesting notions of today's world. Identity indicates an attribute, a characteristic. Identities with a feature or characteristic manifest above all differences. The function to be attributed to identity is a function of classification, which indicates differences. Identity in its most general sense includes all the characteristics of the individual. Questions like how an individual perceives himself or is perceived by society are related with the notion of identity. However, personality is an organization. Personality is the organization of the individual with and within identities. Considering that culture is the major determinant of identities, the rigidity or flexibility of culture also determines that of identity. Various forms of belonging prevail with reference to definition of culture, which also shape the identity. "Positive sense of identity" attained by the resolution of the problem of identity development in the adolescence period is necessary for inhibition of psycho-neurotic and neurotic problems. Development of such a sense of identity, which may be considered positive for the individual, is dependent upon the reciprocal nature of individual's relation to the social group in which he lives, that is; to a group, culture or nation. The sense of belonging which is felt most strongly in the adolescence period may be explained as "identification of oneself as a member of a definite community as conscious of existing within it."
\end{abstract}

Keywords: Nation; Identity; Loss of identity; Psychoneurotic identity

\section{Introduction}

Identity is one of the most abused notions of today's world. While almost every one suggests his own definition of the notion, the most important aspect to its definition is disregarded, which is the fact that the notion of identity has been historically handled within the sphere of psychological sciences and a considerable amount of knowledge has been already produced about it. For this reason, defining and discussing the social functions and reflections of identity as presented by the psychological sciences may be useful in eliminating the chaos prevalent in this field. Firstly, the notion of identity belongs to psychological sciences that analyze the behavior, thoughts and feelings of an individual, in short, his spiritual life. Although concepts like social identity may be suggested and discussed, identity belongs to individual before anything else and psychological sciences provide us with a wide range of resources in explaining the individual. We can attain an understanding of situations or indicators called identity generalized for groups of people only through an understanding of the identities of individuals making up those groups [1]. First of all, identity is a notion specific to human being. Identity has two components: the first is recognition and identification, and the second is belonging. Recognition and identification are about how the individual is recognized by society and how he identifies himself, the means of which are language and culture. Belonging becomes apparent when the individual feels himself as part of any social group. The important thing here is that although society may identify the individual with a certain identity, if the individual does not feel himself as part of that society, he cannot be said to have that identity [2]. The notion of identity was dealt with within the field of psychology and social psychology after 1940s. However, with the recognition that society is much more effective than the individual himself in development of his identity as of $80 \mathrm{~s}$, it has been studied mostly in the fields of sociology, social anthropology and politics. In social psychology, the concept of ego has become one of the major topics in the analysis of identity. Ego and characteristics of ego are capable of engendering the individual's behavior and interaction, plans and actions within society. Social behavior constitutes the various characteristics of ego.

In addition, social environment and socialization processes are significantly effective over formation of ego. Social behavior arising from the various characteristics of ego and formation of ego may be taken as terms intertwined with each other. Ego is the product of 
social interaction. Besides, the individual is both a cognitive and instinctive being in terms of reflecting his knowledge about his ego and a social figure in terms of action [3]. In a sense, the notion of identity has a content in which the individual and the social are combined. In social psychology, identity appears as the notion that realizes and maintains the individual's relation to others and society. Identity both realizes the interpersonal relations and the social reality that gives rise to these relations and is derived from the same social reality. "Identity is a composite and intellectual structure with cognitive and emotional dimensions, including the individual's perception of himself as a self-loyal, separate and different being from others whose behavior, needs, motivations and interests are consistent with each other to a certain degree" [4].

\section{Identity from socio-psychological perspective}

The notion of identity meaning identification and positioning oneself is often used in the sense of collective identity. Within this framework, the focus is on national, religious and ethnic identities that refer people to their belongings to various communities [5]. In fact, the so-called "individual identity" includes all of his characteristics in general sense. Both the individual's selfperception and perception of society of him is related with the notion of identity. Identity can be defined as the role that the person undertakes for himself in life and his way of self-perception. For this reason, "search for identity" is one of the important aspects of the individual's development in life. Identity is a sense of subjective continuity, integrity and consistency attained only after a long process of striving. It is again or even merely the answer to the question "who I am" the individual asks himself. The answers given to this question are shaped by various factors related to the individual's both self-perception and perception by others such as physical structure, life experiences, gender, ethnicity, age, social status or career. Formation of identity is a significant psychological process starting with the adolescence period. It may be argued that the environment in which the individual is grown up has a crucial role in development of his identity and that there is also a genetic and biological structure effective in the process other than environment. Leaving the genetic and structural dimension, which is unchangeable aside, it is possible to say that identity is formed through our relations and identifications with other people. The psycho-social dimension of identity is constituted by identifications and learning in childhood and youth. While characteristics adapted from other people and the environment are added to individual's innate characteristics during development of identity, genetic and structural characteristics are also shaped by the environment as a result of which some are blunted whereas some are reinforced. Identity is a multi-dimensional notion, in the development of which four major processes are decisive: spiritual, socio-cultural, political and economic. Absence of any of these four elements of identity would mean a deficiency in the ties that the individual should establish with the society he lives in. The significance of these processes become more apparent when the effect the environment or society to which the individual belongs has in resolution of the crises faced in development of individual identity is considered. Every society has a history, a particular structure of identity that has been spontaneously constituted by a system of cultural and social values. Individuals adopt such structures of identity produced by objective processes outside them through experiencing with them within the society they are born into and grown up.

The process continues with subjectivization of objective identities, enabling the individual to develop a specific and subjective identity that belongs only to himself but that still originates from the objective identity structure that exists outside him. Hence development of a subjective identity is pre-conditioned by the existence of an objective identity structure [6]. The rise of identity is perceived in the form of "sense of identity". Sense of identity indicates that development of identity has attained a certain level. It refers to experience of integration through identification and the sense of confidence arising from it. An individual with a sound sense of identity has ready-made answers to the questions of "what or who am I?" In order to be able to comfortably answer, the individual needs an established sense of continuity and sameness in his individual ego. "Positive sense of identity" attained with the resolution of the problem of identity development in the adolescence period is necessary for inhibition of the rise of psychoneurotic and neurotic problems. Development of such a sense of identity, which may be considered positive for the individual, is dependent upon the reciprocal nature of individual's relation to the social group in which he lives, that is; to a group, culture or nation.

The sense of belonging which is felt most strongly in the adolescence period may be explained as "identification of oneself as a member of a definite community as conscious of existing within it." The anxiety of "not to know what to appreciate" experienced by the individual in this period can only be resolved by the identity granted by the group to the individual and in this way he may be able to develop a healthy "self-consciousness" about "who he is" [7]. In short, with the successful development of identity in the adolescence period, the individual participates into the organism of society and social fabric as a new and healthy cell while society enables this new cell to survive through feeding him up with values, ideals, symbols and norms composing the culture. Together with sense of identity, "sense of unity" which is constituted commonly by society itself within a collective social structure makes individual a part of social ideals. While the individual thereby experiences with social integration in an organized structure, he is also able to constitute his "ego identity" within the same social reality. Finally, it can be concluded that both the individual and society will be able to pursue a healthy life avoiding falling into the trap of depressions with psycho-neurotic and neurotic origins.

\section{Is development of national identity related to that of individual identity?}

Given that the field of individual identity is so ambiguous and complex, the attempt to attain immediate results that may be decisive through suggesting simple explanations for the relation between individual and national identity may be regarded as taking the easy way out. Human being is a "group-being" in ontological terms. Therefore "individual identity" as a response to the question of "who am I?" always has to include the response to the question 
"who are we?", in other words; the elements of membership and belonging as well. For instance, a person may be French, Jewish and female at the same time. Employment of the notion of identity in various senses such as religious, student or scientific identity points to appearance of the individual within society in different aspects. In this respect, each social characteristic refers to another identity. It is through identity that a social characteristic is highlighted as in the case of religious, secular, scientific, linguistic, political, national etc. identities. Religious identity manifests characteristics related to belief, linguistic identity to language, political identity to political views, attitudes and behavior.

Community consciousness is built upon the intersection points of the responses to be given such questions. Without inclusion of these elements of belonging and membership, no framework of adherence as the inseparable element of an integrated identity could be maintained and the individual identity would be doomed to remain fragmented and fragile. The elements of belonging and membership are the culmination points of "the way of perception not with reference to differences but to similarities" developed by the individual as a result of his personality development [8]. For the development of individual identity, community (collective) identity and the consciousness of such identity are necessary. Nevertheless, what we would like to deal with is the relation between national and individual identity. For this purpose, we will first discuss communitarian identity (collective) and national identity, and hence formation of community and nation in psychological terms.

\section{From collective identity and community to nation}

Collective identity is related with consciousness and sense of a definite group of people about themselves; it is an awareness and sense of belonging characterized by the belief that the community has specific characteristics and therefore is singular. In this sense, in addition to factors such as language, culture, religion, history, life space, material conditions, the memory of community appears to be a significant factor in structuring of collective identity. As the totality of conscious or unconscious memories of experiences had and internalized by a community, collective memory indicates what is left from its past, what still continues and what the community does with this past. The attempt by a group or community to identify itself inevitably requires them to have a view of their past. In this sense, collective identity implies immediateness and long continuity as well as a structure and conjecture. Collective identity is a claim of definite groups (ethnic communities) with roots in a given territory to differentiate themselves from other groups and highlight their differences. It is the tendency developed by a group of individuals to identify themselves and to constitute a group whose interests, spaces and social relations can be managed and confirmed from a group perspective. Collective identity reflects not a definite state but a process. Identity of a community changes in relation to other communities and over time. It is impossible to attain a-temporal and a-spatial legal identity. Just as development of individual identity is possible in the context of interpersonal relations, development of collective identity is also possible in the context of inter-community relations. Collective identity is in a way past-oriented since it is built upon a tradition including certain symbols, religious ceremonies, art works, morals, customs, values, beliefs and knowledge, upon an inherited past, in short it is constituted on the basis of collective memory.

According to Berque (1978), collective identity contains several opposite aspects:

1. Identity both gives a sense of security and evokes action.

2. Identity includes both continuity and transformation; there is no identity without transformation and for transformation to be possible, it is necessary that it is "we" that transforms.

3. Identity combines objective and subjective characteristics.

4. Identity is a totality, but it can also be decomposed.

5. The various aspects, actors and categories of identity may be replaced with each other.

The characteristics of identity may be ranked as follows:

1. Collective identity is perceived and experienced by the group members subjectively.

2. Collective identity is defined as a contrast in opposition to another and as a difference from others.

3. It originates from consciousness of belonging to the group.

4. It is considered within the system of various representations, which include several negative (things to avoid) and positive (ethnocentric assumptions) aspects [9].

\section{Notion of nation and national identity}

In the literature on the notion of nation, there may be found three different approaches:

1. Primitive or primary approach.

2. Ethno-symbolist approach.

3. Modernist approach.

According to the primitive or primary approach, nations have existed since the emergence of language. This approach considers language as the only essential element constitutive of nations. From this perspective, groups of people with different languages have already different set of values, beliefs, knowledge and common past. Collective identities sharing such common elements are sufficient to represent a nation. According to the ethno-symbolist approach, the nation is product of history and expression of the collective spirit of community. The encompassing totality which maintains commonality is the tradition rooted in the past and the natural organic ties of membership to a living community of race and language. This approach suggests that various nations have an irreducible heterogeneity among each other and that there is absolute diversity between nations at best and an irrepressible conflict at worst. In this sense, it tends to a vision of nationalism distancing itself from cosmopolitism. The modernist or contractbased approach suggests a notion of nation as "the unity of partners living under a common law". This nation consists of individuals equal in terms of their rights and duties who recognize such equality with 
others reciprocally. In short, nation is based on agreement with the principles of social contract and includes a free contract or a willing unification. According to Anthony Smith, gender, space or county/ territory, socio-economic class and religion are categories and roles constitutive of the individual "ego".

Smith defines the major characteristics of national identity as follows:

1. A historical territory/country or motherland.

2. Common myths and historical memory.

3. Common mass public culture.

4. Legal rights and duties holding for all members of community.

5. Common economy in which members of community are able to travel freely in the country.

Therefore, in Smith's sense, nation can be defined as the human community sharing a historical territory/country, common myths and historical memory, mass public culture, common economy, and common legal rights and duties [10]. Each community is not a nation. In order for a community life to be raised to the level of nation, ethnicity and socio-psychological reflexes are perhaps necessary but not sufficient. In order to become a nation, beyond sociobiological reflexes, it is necessary that community's consciousness of unity has to be as developed as to be organized in cultural and political terms. Nation corresponds to a much more developed community than human communities the consciousness of unity of which derives from ethnicity or that share a common cultural identity or language. Being organized in cultural and political terms means to establish and maintain a state that builds and controls a system of rights and duties binding for all individuals [7].

Nation is the community which organizes its existence in cultural and political terms. In such a community, the individual feels himself as member to this formation not through manipulations but in a spontaneous manner; and he adopts elements from that spirituality which he can integrate with his identity easily. State is the organization to which nation willingly delegates the legitimate use of power. Nation is the form of community of modern times. National identity is a spiritual formation brought about by living together under a nation state which integrates with and embraces all individual identities in the nation as to become an internal sense of their identity. There can be no question of national identity where nation state does not exist. There can only be oppositional discourses of national identity [11]. "Nation state" and "national identity" are built upon the preceding state and identity, that is, upon tradition, however it also requires rupture with them to the extent that "the modern" is separated from the traditional. Nation state is a modern organization and naturally employs rationality and technology as the characteristics of modernity. Just as modern rationality and technology is differentiated from traditional way of life and techniques, nation state and national identity are also differentiated from their historical antecedents. One of the most important aspects of such differentiation is "building from above to below" on the basis of reflection. This is precisely why each modern nation state, including the most democratic ones, attempts to constitute a "civil religion" (official ideology) including a series of political doctrines, historical narratives, exemplary personalities, celebrations or commemoration ceremonies. Nevertheless, despite "building from above to below" introduced by modern technologies of government, the essential element is the historical-spiritual existence of the nation and the waves it creates "from below to above" [12]. As a result, it may be concluded that individual identity is strongly connected with national identity in terms of either adopting or opposing against it.

\section{From national identity to multiculturalism or from nation state to rainbow society}

Modernism's emphasis on universality was established on the representation of a unique, rational and integral subject. Postmodern thought first attempted to challenge against universality and to understand subject from a more fragmented, decentered and irrational perspective. Considered together with the social movements of 68 , this brought with itself an increase in the interest in the marginal and the minor, or in other words, in the "other" [13]. The unitary structure of the nation state centered upon one national identity as inherited from French Revolution has required denial or assimilation of "the other" or "the different" up to a recent time. Nation states with their policies even sometimes including violence have been usually distant from recognizing and approving the other or the different [14]. The notion of diversity has several interpretations. For this reason, it is necessary to explain what difference is before introducing any debate or analysis on this notion [15].

According to Williams \& 0 Reilly [16], difference is defined "any characteristic used by a person to discover his individual differences" [17] while in a study conducted by Jackson, Joshi \& Erhart [18], difference is defined as "distribution of personal characteristics among the independent members of a working unit". Differences are also designated as "differences among people in terms of race, culture, gender, sexual orientation, age and physical capabilities". Some definitions of difference also include various other dimensions like ethnic origin, national origin, class, religion, learning and communication style, place of birth or vocation [19]. As a matter of fact, according to McGrath (1995) who argues that differences should not be considered only in demographic terms, difference is "the totality of characteristics related to demographic determinations (race, gender, age, etc.), vocational knowledge and skills, values, beliefs and attitudes, personality, cognitive and behavioral styles, status in an organization" [20].

With the success of the social movements of 68 , the notion of difference has led to cracks in the so-called traditional policies of nation state. The collapse of Soviet Block also led to the replacement of the universal policy of liberty with a new conception of politics taking multiple social dynamics into consideration [21]. Today nation states pursue a social politics much more sensitive to the differences. Especially considered within the context of debates on globalization, it is seen that while cultural identity tends to 
homogenize in some respects, the emphasis on sub-identities (ethnic, religious or gender identities) is prevailing. Therefore, it has become necessary to consider the process at work not only as a matter of homogenization but also as a totality including heterogeneity as well. Within such a framework, "multiculturalism" appears to be introduced as a fundamental concept of the debates carried out. "Politics of recognition", "identity politics" and "politics of difference" are other important concepts employed in order to explain the same process [22]. Multiculturalism is one of the popular notions employed in conformity with the spirit of the age (zeitgeist). It literally means "co-existence of many cultures in a country". However, it is also a nebula notion the limits of which tend to fade, dim or evaporate as much as it is debated. It has a conjectural dimension as well. It is observed that while metaphors like pot, salad, mosaic, kaleidoscope or rainbow were used in $60 \mathrm{~s}$ in order to designate differences in a country, today reference is mostly made to the notion of multiculturalism in order to describe the same facts. This also means that it implies different solutions and aspirations changing in parallel to countries or problems it is applied to. The concept of culture employed in social psychology and political science is used in a manner similar to that of ethnologists or anthropologists. Culture including "everything added by human beings to nature" denotes a totality of modes of behavior attained within a human community subsequently. The so-called culture points out to the beliefs that expresses belonging of people to a community and "fixes their communitarian identity".

In technical terms, it is a product of an intimate order experienced in face to face, sincere and immediate relations [23]. The notion of identity in the sense of identification and positioning of oneself usually refers to collective identity. It is in this framework that the focus is oriented to national, religious and ethnic identities, which refers people to their belonging to various communities. The notion of community is more problematic. In general, community is a religious, ethnic or cultural group of people with common interest and goals living together. It is also employed in a broader sense as to refer to an urban community, a nation, a union of states and even international community. It can also imply religious communities, mystic groups, terrorist organizations, trade unions etc. That the members of the community have a sense of solidarity with each other or the totality of the community, or that they have the same beliefs and pursue the same individual or collective goals is not sufficient to differentiate types of communities from each other [24].

Considered from this perspective, community may refer to very different groups such as radical groups on one extreme and mutual ones based on belonging on the other or anti-democratic groups on one extreme and democratic ones on the other. According to Tenzer [25] a community cannot be considered independent of a conflict with another community which may include both participations and separations. Leaving aside the extreme cases, in an intermediary sense, communities are, on the one hand, oriented to protection and expansion of particular traditions, encouraging acting in solidarity with the internal group compared with the general society or to sublimation of the external indicators of identification with the group. On the other hand, they try to maintain "integration with the general society and conformity of particularity of the group with the common law" in the remaining fields. Tenser suggests that in its modern and secularized from, community refers to a group sensitive in some respects such as pressure or interest groups claiming for equality of rights, respect for truth or historical memory. Nevertheless, with the politics of identity, the notion of community has ceased to be only a sociological category or descriptive notion applied to archaic or traditional organizational forms or "their residues within modern society". In addition, it implies a primitive and natural state antecedent to the voluntary intervention of the person or a challenging condition like a concrete and biological reality. However, such conceptions are built upon an assumption of "a united humanity as necessary and natural existence of common life and thought", which tends to be radicalized and results in ideological implications [26]. The transition from community to society has taken place in the end of the past century and in the midst of industrialization. However, today the process is reversed. The general networks of production, consumption and communication founded on the residues of modern society and institutions are seen to transform into communities. Everywhere the number of groupings based on identity, societies founded upon common belonging, sects, cults, nationalities is increasing, and societies are increasingly turned into communities. This is why multiculturalism is highly debated and spreading as a current of politics today [27].

Multiculturalism may designate different political projects changing from country to country. It may pursue sometimes expression of cultural differences in the public space and sometimes granting special rights to minorities and even certain privileges that would enable to enhance their conditions and compensate for their deficiencies. In this sense, politics of multiculturalism is different from multiculturalism in the sense that it pursues ideological construction of society around certain projects and normative proposals rather than describing the sociological reality or suggesting an ethnographic determination. This is political multiculturalism which includes a construction activity oriented to sublimation of an alternative vision of "common good" and "truth". From a perspective in favor of persons and groups claiming for a singular identity, institutions, mechanisms, norms and values of society are subjected to continuous negotiation. In addition, politics of multiculturalism includes orientation of actual public policies with reference to a definite understanding of public policy, that is, to an ethical and philosophical ideal [28].

The attractiveness of politics of multiculturalism derives from its containment of a rich and pluralist conception and assumption in terms of human potentials within a political totality [29]. The current prevalence of politics of multiculturalism may be related to certain social processes: the discovery of cultural diversity and identity differences which become increasingly more important for groups that have various origins and life styles but have to find a way of living together or in parallel to the transition from industrial to post-industrial society, renewal of culture as the center upon which the communitarian claims are built. And finally, the crisis of 
the holy state and normative institutions increases the number of supporters and influence of the tendency of weakening of the central institutions of social ties [30]. Multiculturalists claim that they are "concrete realists", where concrete reality refers to the "subjective reality" that people are. For this approach, when a group of people believe that they are "together" and "among themselves", a culture arises, in which everybody may choose, list or internalize any origin they prefer. Nevertheless, the representations are conducive to fade away or evaporate and their authenticity may suddenly become reversed. The identity supposed to be shared may lose from its value and result in a new crisis of identity. Is it logically possible to hold the belonging assumed to be necessary and such subjectivity together? Some communitarians tend to construction of cultural totalities linked to communities through production of a mythical history and suggest taking roots in "concrete" groups as an alternative to liberalism's abstract construct of citizen. They claim they are not constructivist but realists. Nevertheless their assumption that "depending upon the concrete aspects of natural communities rooted in tradition and history is more realistic compared with construction of artificial totalities based on abstract principles" is also controversial given that "from this perspective which has its roots in Burke and German romantics, the communities supposed to be concrete with their integrative traditions and cultures are in fact constructed within a mythical abstraction which reduces their complexities" [31]. The multiculturalist discourse is a culturalist anthropological conception at the base of which lies cultural relativism. It departs from the obvious fact of diversity of cultures in reality to move to plurality of cultures. However, diversity of cultures does not necessarily include plurality or discontinuity of them. The thesis of plurality is based on postulation of a separate unity or consistency of a culture focused on itself. The logic here is indistinguishable from the logic of racism. When physical characteristics are extracted from classical racism which deduces plurality of races from diversity of our genetic characteristics, what remains is the essence of culturalism: "A community has an intrinsic and singular mode of existence inscribed in its language, art, religion and political organization" and each element can be understood only in its relation to totality.

However intercultural interdependency and interactions are extremely broad dimensions and human culture displays continuity [32]. It may be argued that the cases of Northern Europe countries which are supposed to be multiculturalist is rather in conformity with the model of "society based on agreement with central values" and the fact that these countries are nationalist rather than multiculturalist supports the idea that the notion of nation has a universal scope. The national values such as liberty of selfrealization, equality in social competition and fraternity against xenophobia are also suggested by supporters of national identity. The persons identifying themselves as nationalist repeatedly reflect upon common culture in order to be able to render it really universal and openly discuss on the questions of cultural diversity. Restoration of communities for the sake of esthetics of multiculturalism also appears to be risky in sociological and sociopsychological terms. All along history communitarianism in small or large groups has always appeared together with "exclusion", which is its intrinsic characteristic. History of traditional societies as well as studies by contemporary social psychologists point out to this fact $[33,34]$.

Conception of multiculturalism by its supporters as contemporary, innovative and even as the spirit of the age (zeitgeist), in short, as conformable to the way of the present world reinforces the tendency to perceive and represent people questioning multiculturalism to be outdated, in favor status quo, conservative etc. Above all, the imports of discourses on this issue differentiate according to the point of view and concrete cases. More importantly, like the supporters of multiculturalism, its opponents also do not belong to any specific ideological camp as right or left and do not hold any constant position. For instance, a French intellectual Elisabeth Badienter says: "I have two characteristics: I am both female and Jewish. I detest being labeled by any of them, for I am a French citizen as a member of national society. I especially insist on this, because after I struggled for the right of difference in my youth, I now see that Le Pen also argues for that: Yes, you are different, and you should stay where you are. I thereby understand both the significance and value of being indifferent. Highlighting differences instead of similarities and common aspects means exclusion and then to provoke sources of conflicts" [2].

\section{Conclusion}

\section{The need for nation state and national identity again}

While the world is increasingly presenting a fragmented structure, considering the problems in these fragments from a perspective of total solution would lead to negligence of particularities of localities and hence would be misleading. For this reason, maintenance rather than dissolution of "national identities" seems to prevail as a useful system of meanings that would help solution of problems. The comprehensive but paradoxical change the world has been undergoing brings several psychological and sociological problems together with itself. The mechanism to solve these problems should be looked for in the psychology of the individual as the smallest building stone of the system where the problems can be observed most clearly. The individual would feel that his individual identity is also threatened in the face of change with the regress, erosion and disvaluation of national identity. In the context of such an internal chaos, he would either violently react against the new identity fastened to him instead of his previous identity or have to adopt the new identity in an instinctive and irrational manner. The promises of this artificial identity to solve internal knots would bring about new and more complex identity illusions due to the inadequacy of the historical, sociological, cultural and political background on which these promises are built upon.

It would seem that the questions and dilemmas arising in the individual's mind could be resolved with narrow definitions of identity. As a result, the individual would hold fast to micronationalities cherished by ethnic characteristics, ancestral ties and historical processes and in fact would choose to identify himself 
in a very narrow manner. The structure to arise when the national identities based on individual identities are shattered would be probably similar to the structure of sets of indicators arising in the case borderline personality disorders. Adding the differences provoked in terms of sexism, the scene of borderline would become even more chaotic due to the complexity of sexual identity. People or communities that are colorful but unaware of who they are and driven to and for by their impulses would blindly wander around. In conclusion, it can be argued that national identity and nation state in which it is to grow are as individual needs as the need for individual identity. National identity and nation state are the necessary structures for the individual to lead a healthy life which have no alternative. Both objective and subjective individual identity and national identity built upon individual identity are in need of being studied by means of dialectic and analytic methods of psychology in addition to the holistic methodology of social sciences. Intellectuals and media organs in our society that favor multiculturalism like other themes conformable to the way of the present world surely with good intentions such as not favoring status quo, reforming the problematic and perverse order, developing democracy, adopting the attitudes of Western intellectuals, supporting the disadvantaged groups etc. rather than looking for the solution of problems from the perspective of national integration should bear the historical responsibility of the outcomes of their attitude.

\section{References}

1. Hakan M (1995) What is identity? Turkey Journal, Cedit Publications, Ankara, Turkey, 33: 146-150.

2. Ardoino J (1999) Editorial, anayses, pratiques de formation. Le Travail de Intercultural 37-38: 5-8.

3. Kağitçibași Ç (2000) Insan human and family in the context of culture. Cultural Psychology. Istanbul, Turkey.

4. Bilgin N (1996) Human relations and identity, System Publishing, Istanbul, Turkey.

5. Bilgin N (1994) Identity problem at the crossroads of social sciences. Ege Publishing, Izmir, Turkey.

6. Kuşat A (2003) Sense of identity as a system of values and Atatürk. Journal of Social Sciences Institute 15: 48-49.

7. Hastings A (1997) The Construction of nationhood: Ethnicity, religion and nationalism. Cambridge University Press, England, United Kingdom.

8. Maslow AH (1971/1980) The Farther Reaches of Human Nature. Viking Press, New York, USA.

9. Bilgin N (1999) Collective identity, System Publishing, Istanbul, Turkey.

10. Smith AD (2004) National identity. Communication Publications, Istanbul, Turkey.

11. Gökan E (2005) Identity politics. Turkey Diary Journal, Cedit Publications, Ankara, Turkey, 83: 17-26.

12. Miller Do (1999) On Nationality, Clarendon Press, Oxford, United Kingdom.
13. Altunoglu M (2005) Two different multicultural comments. Turkey Diary Journal, Cedit Publication, Ankara, Turkey, 81: 73-88.

14. Kymlicka W (2004) Introduction to contemporary political philosophy. Istanbul Bilgi University Publications, ( $1^{\text {st }}$ edn), Istanbul, Turkey.

15. Hubbard EE (2004) The Manager's pocket guide to diversity management. HRD Press, Inc. Amherst, Massachusetts, USA.

16.0 Reilly CA (1998) Beyond simple demographic effects: The importance of relational demography in superior-subordinate dyads. Academy of Management Journal 32(2): 402-423.

17. Mannix E, Neale MA (2005) What differences make a difference? The promise and reality of diverse teams in organizations. Psychological Science in the Public Interest 6(2): 31-55.

18. Jackson SE, Joshi A, Erhardt NL (2003) Recent research on team and organizational diversity: SWOT analysis and implications. Journal of Management 29(6): 801-830.

19. Sonnenschein W (1997) The Diversity toolkit: How you can build and benefit from a diverse workforce. McGraw Hill Companies. New York, USA.

20. Point S, Singh V (2003) Defining and dimensionalising diversity: Evidence from corporate websites across Europe. European Management Journal 21(6): 750-761.

21. Müftüoğlu A (2003) Anti-liberalism of cultural liberalism Toplum. Society and Science. Istanbul, Turkey, 96: 166-184.

22. Zizek S (2002) Fragile Contact, Metis Publications, Istanbul, Turkey.

23. Grosser A (2003) The Europe of daily life and intimacy in Europe identite plurielle, Paris, France, p. 17-46.

24. Bilgin N (2005) Multiculturalism and national identity. Turkey diary magazine, Cedit Publications, Ankara, Turkey, 80: 52-65.

25. Tenzer N (1995) Communitarianism against the community. The Banquet, Political Review of CERAP 7: 155-173.

26. Levy A (1995) Les sciences Clinique's et les organizations socials, PUF, Paris, France.

27. Touraine A (1997) Critique of Modernity. Fayard, Paris, France.

28. Costant F (2000) Multiculturalism. Flammarion restaurant reviews. Paris, France.

29. Weiler JJH (1998) Fundamental rights and fundamental limits. In: Kastoyano R (Ed.), What identity for Europe? Sciences Po Press, Paris, France, p. 119.

30. Constant F (2002) Self-selection, earnings, and out-migration: A Longitudinal study of immigrants to Germany, Institute for the study of labor. IZA DP No. 672

31. Lukes S (1995) Social attachment and its myths: On the quarrel between liberalism and communitarianism. The banquet, Political Review of CERAP 7: 174-190.

32. Pierrot A (1998) Le Multiculturalism, in integration et exclusion. In: Ferreol G (Ed.), Presses Universities de Lille, France, pp. 229-261.

33. Mosques C (1998) Communities and social link, in Integration at exclusion. In: Ferreol G (Ed.), University Presses of Lille, France, pp. 428439.

34. Suavi A (1999) Identity problem, nationality and Turkish identity. Other Publications, Ankara, Turkey. 